\title{
KNJIGE O BRANJU IN NEBRANJU - OGLED NOVEGA ŽANRA
}

Ključne besede: knjige o branju in nebranju, bralne avtobiografije, bralni priročniki, diskurz o knjigah

\section{Uvod}

Zadnjih nekaj let je lahko vsakdo, ki spremlja sodobno produkcijo s področja raziskav knjige (ang. book studies), opazil, kako bliskovito se je namnožila literatura, ki tako ali drugače obravnava branje. The Joy of Reading (Užitek branja), Bookworms (Knjižni molji), A Passion for Books (Strast do knjig) je samo nekaj tipičnih naslovov. Razlogov za ta trend, ki ga je mogoče intenzivneje zaznati nekje po letu 2000, si ni težko zamisliti: lahko ga razumemo kot odziv na napovedovan zaton branja, ki naj bi izgubljalo bitko s ponudbo zabavnih elektronskih medijev; lahko ga imamo za komentar na izjemno število (vsako)letno izdanih knjig ali na domnevno dematerializacijo knjige ob prihodu e-branja. Morda pa gre preprosto za nanovo odkrito tržno nišo. V vsakem primeru je pohod tovrstne literature odraz aktualnega stanja in spreminjanja predmetnosti knjige, kakršno smo poznali doslej. V prispevku želim s pregledom sodobnih knjig o branju analizirati načine, kako portretirajo branje in kako artikulirajo $s$ tem povezana doživetja, ob tem pa premisliti, kaj vse to pove o sodobni bralni kulturi. 


\section{Knjige o branju - poskus definicije $e^{1}$}

Najprej pojasnilo: knjige o branju niso teoretske študije literarnih znanstvenikov. So veliko bolj poljudnega značaja in bi jih lahko na široko opisali kot knjige, ki obravnavajo bralne prakse, protokole in repertoarje ${ }^{2}$ in tako ali drugače naslavljajo vprašanja, kot so: kaj, kako, kje, kdaj in zakaj beremo, kdo bere kaj, kako dolgo, koliko in s kom; pri tem pa kažejo zanimanje tudi za otipljivo materialnost branja. Ker praviloma govorijo o branju nasploh, izključujejo študije posameznih avtorjev in konkretnih del. Največkrat so pisane v izrazito osebnem stilu, zato mednje ne sodijo niti zgodovine branja niti večina didaktičnih in pedagoških študij in priročnikov za hitro branje, še najmanj pa razprave o recepciji, »bralčevem odzivu« ali »natančnem branju « ${ }^{3}$ oziroma sploh kakršnakoli strokovna analiza. Knjig o branju tudi ne gre enačiti s knjigami o knjigah, ki predstavljajo veliko širšo in splošnejšo kategorijo in so jih pisali že v antiki, ${ }^{4}$ a jih na tem mestu ne moremo podrobneje obravnavati.

Na prvi pogled se torej zdi, da pisanje o branju nima silno bogate bibliografije. Kljub temu ga lahko zasledujemo že daleč nazaj v zgodovino. Montaigne je o branju pisal v svojih Esejih, prav tako Coleridge in Hazlitt. ${ }^{5}$ A nekako do 20. stoletja je bilo pisanje o branju praviloma omejeno na eseje in se je največkrat pojavljalo v okviru bibliofilskih zbirk spominov, anekdot in citatov pod taktirko enega ali več urednikov. Šele postopoma je branje kot táko, torej ne (samo) v pomenu prebranih knjig, temveč kot nadvse raznolika življenjska praksa sama na sebi, preraslo v obravnave vre-

1 Zaenkrat še nisem zasledila nobene razprave na to temo; tukajšnje besedilo je poskus v tej smeri.

2 Koncept repertoarja si sposojam pri J. Hermes (Reading Women's Magazines, 1995), vendar z njim nekoliko drugače opisujem predvsem pomene, ki jih avtorji pripisujejo in razbirajo iz svojih bralnih navad.

3 Natančno branje je prevod angleške sintagme »close reading «; povzemam ga po prevodu T. Virka (Moderne metode literarne vede in njihove teoretske osnove, 1999).

4 Gl. na primer O poznavanju knjig Telefusa iz Pergamona, Izbira in nabava knjig Herenija iz Biblosa in Bibliofil Damofila iz Bitinije.

5 M. de Montaigne: »On three kinds of social intercourse«, v: Essays, ok. 1580; S. Coleridge: "Lectures on the principles of poetry«, v: Lectures on Literature, 1808-1819, vol. I; C. Lamb: »Detached Thoughts on Books and Reading «, v: Essays on Elia, 1823; W. Hazlitt: »On Reading Old Books«, v: The Plain Speaker: Opinions on Books, Men, and Things, 1826. 
dno temo. V tej luči je bilo $\mathrm{z}$ redkimi zgodnejšimi izjemami v resnici šele v drugi polovici 20. stoletja, izraziteje pa od devetdesetih, prepoznano kot nekaj, kar lahko vzbudi širši interes in kar je mogoče raziskovati na ravni resne knjižne študije.

Zbirke in antologije na temo branja so sicer ostale "v modi«, vendar so se ob njih začele pojavljati tudi monografske raziskave bralnih užitkov, kot so: Ruined by Reading: A Life in Books L. S. Schwartza (Uničena od branja: Življenje med knjigami, 1997); How Reading Changed My Life Anne Quindlen (Kako je branje spremenilo moje življenje, 1998) in The Complete Polysylabic Spree Nicka Hornbyja (Popolna večzložna veselica, 2006). Med njimi je mogoče razločiti zlasti dve vrsti knjig o branju: izrecno avtobiografske knjige o ugodju branja in bralne priročnike.

\section{Bralne avtobiografije}

So Many Books, So Little Time (Toliko knjig, pa tako malo časa), Sara Nelson, 2003; Leave Me Alone, I'm Reading (Pusti me pri miru, berem, Maureen Corrigan, 2003); Ex Libris, Confessions of a Common Reader (Ex Libris: Izpovedi običajnega bralca, Anne Fadiman, 1998); A Reading Diary (Bralni dnevnik, Alberto Manguel, 2004). To je samo nekaj reprezentativnih naslovov bralnih avtobiografij. Brez dvoma je vsaka knjiga samosvoja, vendar je med njimi mogoče zlahka prepoznati skupne poteze: tematizacija branja kot ugodja; poudarek na osebni izkušnji; natančno opazovanje lastnih bralnih navad; pripoznanje »telesnosti« knjig in branja; antididaktični pristop in konverzacijski stil pisanja oziroma zaupniško naslavljanje bralca.

Med bralnimi avtobiografijami so gotovo najprepoznavnejši t. i. bralni dnevniki - osebni spomini na branje in prebrano oziroma nekakšni bralni samoportreti, popisani na ozadju vsakdanjega življenja. Toliko knjig, pa tako malo časa Sare Nelson denimo temelji na enoletnem projektu branja in pisanja o po eni knjigi na teden, kar bi lahko označili za neke vrste samoizzvani resničnostni šov. 
Kaj pravzaprav pričakujem od takšnega popisa svojih branj? Moj namen ni spisati 52 recenzij. [...] To, česar sem se lotila, je poskus spraviti na papir, kar sem vsa ta leta počela $\mathrm{v}$ mislih: povezati svoje bralne izkušnje $\mathrm{z}$ osebnimi in opazovati, v čem vse se prekrivajo ali ne. (Nelson, 2003, 7) ${ }^{6}$

Motivi drugih pišočih bralcev so zelo podobni: bralca nimajo namena izobraževati niti jim ne gre izrecno za promocijo branja, pa čeprav se zdi, da je to pogosto končni učinek takšnih knjig. Še najbolje bi lahko njihovo pisanje opisali kot nekakšno navdušeno opisovanje lastnega užitka. Manguel takole pojasnjuje vzgibe za pisanje svojega Bralnega dnevnika:

Pred nekaj leti, po mojem triinpetdesetem rojstnem dnevu, sem se odločil ponovno prebrati nekaj mojih najljubših knjig in presunilo me je, kako njihovi večplastni svetovi preteklosti odsevajo kaos sveta, v katerem živim. Odlomek iz romana je nenadoma osvetlil članek iz časopisa, neki prizor mi je priklical v spomin napol pozabljen dogodek, ena beseda je spodbudila daljše razmišljanje ... Odločil sem se, da bom te trenutke beležil. Prišlo mi je na misel, da bi lahko, če bi vsak mesec ponovno prebral po eno knjigo, v enem letu spisal nekaj med osebnim dnevnikom in "priložnostno knjigo «: ${ }^{7}$ zvezek zapiskov, pripomb, premišljevanj, vtisov s potovanj, skic prijateljev, javnih in zasebnih pripetljajev, ki bi jih vse spodbudilo branje. (Manguel, 2004, x)

Bralec, ki s tem postane pisec, tako upa, da bo v svojem branju razbral kakšen vzorec, uzrl nov pogled na lastno življenje - skratka, spoznal nekaj o sebi samem:

Poskusila sem ugotoviti, zakaj berem tisto, kar berem, kako ena knjiga vodi $\mathrm{k}$ drugi in kaj vse to pove o meni, mojem življenju in naravi branja samega. (Nelson, 2003, 8)

Zdi se mi, da to, kar si izbiram za branje, sestavlja nekakšno pripoved, da ena knjiga vodi $\mathrm{k}$ drugi in da prebrano zarisuje teme in vzorce, ki si jih je vredno pobližje ogledati. (Hornby, 2006, 1)

6 Vsi prevodi so delo avtorice članka.

7 Commonplace book je največkrat oznaka za beležko, kamor si bralec prepiše izbrane odlomke ali citate iz knjig. 
Poskus Maureen Corrigan deluje kot raziskovanje svoje lastne identitete:

Moja knjiga je poskus ugotoviti, kakšne posledice je imelo moje predajanje knjigam, in raziskati, kako je branje spremenilo moje življenje, večinoma na bolje, včasih pa tudi na slabše ... Z mojimi bralci bi rada delila ta spoznanja in njihove učinke na moje lastno življenje. (Corrigan, 2005, xvi)

V vseh teh knjigah se zdi doživljanje branja kot užitka nujni predpogoj za branje in še posebej za pisanje o branju in je tudi predstavljeno kot tisto, za kar se je treba zavzemati. Da lahko branje dojamemo kot užitek, pa moramo najprej sploh brati iz užitka. To prepričanje je pogosto izraženo z odkritim nasprotovanjem vsakršni obliki prisilnega branja: »Če ti knjiga ni všeč, jo nehaj brati, « pravi Sara Nelson $(2003,56)$. »Nihče ne bi smel brati knjige, v kateri ne uživa, ne glede na to, kako priljubljena je in četudi ima še tako dobre kritike, « je prepričana tudi Nancy Pearl (2003, xii).

Takšno stališče krepijo priznanja avtorjev o svojih lastnih »bralnih luknjah«, ki kvarijo njihovo podobo univerzalnih knjižnih moljev. Bralna avtobiografija Sare Nelson je polna njenih izpovedi o domnevno silno pomembnih knjigah, ki bi jih morala prebrati, a se ni mogla prebiti skoznje. $\mathrm{Na}$ koncu enega ob drugem celo objavi seznama »Kaj sem nameravala prebrati« in »Kaj sem dejansko prebrala» (2003, 233-240), pri čemer je prvi precej daljši od drugega.

Bralnim avtobiografom je skupen tudi sproščeno klepetav nagovor bralca, ki se lepo ujame z užitkarskim odnosom do knjig. Vsakršen občutek sramu ali nelagodja glede tega, kaj kdo bere, velja za povsem neprimernega in kot nekaj, proti čemur se je treba boriti:

Vsi bi morali brati iz užitka. [...] Nič hudega se ti ne bo zgodilo, če ne boš prebral romana, ki je dobil letošnjo nagrado Booker, in nič dobrega se ti ne bo zgodilo, če ga boš. (Hornby, 2006, 7-8; orig. poudarki)

Če tovrstne bralne avtobiografije sploh promovirajo kakšno razsvetljenje skozi branje, gre potemtakem kvečjemu za razsvetljenje skozi ugodje branja. Rečeno drugače: prej kot da bi z bralci delili svoje znanje, ti avtorji delijo svoje ugodje. Ta antididaktičnost je večkrat odkrito priznana: »Na 
kraj pameti mi ne pade, da bi vam govorila, kaj naj berete« (Nelson, 2003, 7). Skratka, literatura je vseskozi vrednotena glede na užitek, ki ga ponuja.

Kljub temu, da so avtorji bralnih avtobiografij praviloma poklicni bralci in pisci - kritiki, uredniki, novinarji, profesorji ali pisatelji ${ }^{8}$ - in so le redko povsem neznani, si v vlogi popisovanja lastnega branja vsi po vrsti prisvajajo glas običajnega bralca - pristop, ki ga je v zbirki z istim naslovom, The Common Reader (1938), znamenito ubesedila Virginia Woolf (pa četudi ga $\mathrm{v}$ njenem lastnem pisanju $\mathrm{v}$ resnici ni čutiti):

Običajni bralec se, kot je vedel že Dr. Johnson, razlikuje od kritika in učenjaka. Je slabše izobražen in narava ga ni tako bogato obdarila. Bere iz lastnega veselja in ne za to, da bi delil znanje ali popravljal mnenja drugih. Predvsem pa ga vodi želja, da bi iz vsega, kar mu pride naproti, ustvaril neke vrste celoto - portret človeka, skico dobe, teorijo umetnosti pisanja. (Woolf, 1983, 1)

Ne glede na svoje knjižne kariere, knjigoljubi avtorji puščajo ob strani svoje poklicne "jaze« in se raje pokažejo kot skromni zasebniki, ki bralce vseskozi naslavljajo kot sebi enake. ${ }^{9}$ Branje je njihovo individualno prostočasje, ki zajema pretežno leposlovje in tako omogoča, da se meditacije zlijejo $\mathrm{z}$ romanesknimi prigodami in literarnimi junaki.

Še ena skupna poteza bralnih dnevnikov je njihov poudarek na materialnosti knjige in fizičnosti branja - kot na primer v tejle opazki Anne Quindlen:

Imela sem okoli deset let, ko mi je gospa LoFurno začela posojati knjige iz svoje kleti, knjige brez plastičnih platnic, brez knjižničnih oznak v rjavih kartonskih žepkih, popisanih z imeni vseh ostalih, ki so jih že prebrali. Mnoge njene knjige

8 Sara Nelson je urednica, kolumnistka in literarna kritičarka; Nancy Pearl je kritičarka in knjižničarka; Anne Fadiman je urednica in novinarka; Anna Quindlen je romanopiska, prav tako tudi Nick Hornby itd.

9 Kljub temu so knjige o branju pogosto privlačne prav zaradi slave avtorjev. Nanjo največkrat opozarjajo že sami naslovi: Najčudovitejše knjige: pisatelji o odkrivanju bralnih užitkov (M. Dorris in E. Buchwald (ur.), 1997); Iz ljubezni do knjig: slavni pisatelji o svojih najljubših knjigah (R. B. Shwartz (ur.), 1999); Pesmi za življenje: slavni ljudje izbirajo svoje najljubše pesmi in govorijo o tem, zakaj jih navdihujejo (A. Quindlen, 2005); 17 pisateljev o svojih ljubih knjigah (A. Fadiman, 2006). 
so bile starejše, s tistim posebno sladkim prašnim vonjem, ki ga imajo stare knjige; in imele so rjavkasto črne ekslibrise, ki so me spominjali na drugačen svet ... (Quindlen, 1998, 24)

Knjige niso predstavljene kot častitljivi dragoceni objekti za na razstavo, temveč so zelo konkretno »v rabi«: bralci in bralke jih "požirajo« med kuhanjem, pri jedi in v kopalni kadi; nekaterim služijo tudi kot pohištvo:

Ko sem bila še študentka, sem živela v majhnih stanovanjih, kjer so bile knjige glavni kosi pohištva. Kup velikih namiznih knjig o umetnosti in arhitekturi 19. stoletja je nadomestil kavarniško mizico; mehkoplatnične izdaje so popestrile bledikave stene in antologije viktorijanske poezije in prozna dela so bila podstavljena pod mojo posteljo. (Corrigan, 2005, 56)

Še več: ker jih opisujejo v vsej njihovi materialnosti in z močnim čustvenim nabojem, o njih neredko razpravljajo kot o ljudeh:

Svoje knjige izbiram tako, kot izbiram svoje prijatelje: za knjigo se odločim, ker naju je nekdo predstavil, ker mi je bila všeč na videz, ker so najboljše med njimi obenem pametne in smešne in presenetliive. (Nelson, 2003, 4)

Sara Nelson govori o "prvem vtisu« (platnice, naslov, prvi stavek), o tem, kako se težje prepusti kratkim zgodbam, in, kar je najpomembneje, o tem, kako se v knjigo zaljubi.

Kot takšni so bralni dnevniki in (avto)biografije kombinacija osebne pripovedi in meditacije o lastnem branju, prepletene s komentarji na romaneskne zaplete. A to še ne pomeni, da bralec kaj izve o vsebini obravnavanih del. Če avtorji ponudijo kratke obnove, dobi bralec vpogled v dva svetova - $\mathrm{v}$ avtorjevega osebnega in $\mathrm{v}$ fiktivnega, pri čemer je drugi prikazan posredno prek prvega. Če kot bralci poznamo dela, o katerih piše avtor, je branje še posebej zadovoljivo, a tudi če jih ne, to ni ovira, saj vsebina večinoma ostaja na ravni mimobežne reference: zgodbe so prejkone avtorjev izgovor, da lahko govori o sebi. Dejansko se nam lahko zgodi, da bomo natančneje sledili avtorjevim osebnim razodetjem in mestoma morda celo izgubili zanimanje za samo knjigo ali pa sploh pozabili, da gre pri vsem skupaj pravzaprav za pisanje o branju. Težišče je namreč vseskozi na av- 
torju in prav ta osebna dimenzija je tista, ki dela njegovo branje privlačno: bolj ko sebe postavlja v središče pozornosti, manj moteče je, če ne poznamo knjig, ki jih omenja.

Vloga, ki jo v tovrstnih dnevnikih in avtobiografijah igra ponovno branje enih in istih del, razkriva poudarek na osebnem spominjanju. S tem vsakokrat stopi v ospredje enkraten bralni profil, ki te knjige bliža romaneskni prozi. Prav zato se dela med seboj razlikujejo, kot to velja za žanrske romane, ne toliko $\mathrm{v}$ vsebini in formi, $\mathrm{v}$ namenih in predpostavkah, temveč predvsem v svojih individualnih poetikah. Čeprav vsi vzdržujejo berljiv, dostopen jezik, jih loči na primer raven samoironije in samorazkritja. Sara Nelson tako svoje bralne kaprice razkriva v nadvse zabavnem tonu, medtem ko je Manguelova pisava manj izpovedna in bolj nagnjena $\mathrm{k}$ filozofskim meditacijam in političnim komentarjem. Knjige, ki jih omenja, pogosto ostajajo zgolj na ravni miselnega izhodišča.

Kljub temu knjige o branju tvorijo prepoznaven žanr. To potrjujejo tudi novi in novi naslovi - med njimi denimo pred kratkim izšli memoari Susan Hill Howard's End is on the Landing: A Year of Reading from Home (Howard's End je na stopnišču - leto branja v domači hiši, 2009). ${ }^{10}$ Še več, govorimo lahko že o množici avtorjev, ki se specializirajo prav na knjige o branju, kar idejo tovrstnega žanra le še podčrtuje. ${ }^{11}$

Potem ko sem jih prebrala in pregledala, lahko zatrdim, da bralne avtobiografije $\mathrm{v}$ resnici uspešno mehčajo občutek krivde tako glede užitkarskega branja, kot tudi glede ne(zadostnega) branja. Takšno, do neke mere posredno predajanje fikciji je $\mathrm{v}$ resnici zelo pomirjujoča in sproščujoča izkušnja, saj nam sam akt branja omogoča vsaj začasno potlačitev krivde glede neprebranega. Poleg tega se praviloma prav lepo berejo. S tem ko omogočijo vpogled $\mathrm{v}$ zasebna življenja avtorjev bralcev in nas seznanjajo $\mathrm{s}$ knjižnimi motivi, ponujajo kar dvojno zadoščenje. Prav zato pa se zdi, da

10 Naslov se nanaša na avtoričino s knjigami založeno domovanje; Forsterjeva klasika leži pač na stopnišču.

11 N. Pearl je na primer napisala Book Lust (2003), Now read this: A guide to mainstream fiction, 1998-2001 (1999), Now read this II (2002) in Now read this III (2010). A. Fadiman je (ob omenjenem) tudi avtorica dela At Large and at Small - Confessions of a Literary Hedonist (2007). Dodatni dokaz priljubljenosti žanra so vse številčnejši "pripomočki«, kakršni so lični zvezčiči za popisovanje bralnih avantur (gl. na primer A Book Lover's Diary in A Book Lust Journal). 
lahko uspešno naslavljajo samo tiste, ki tudi v resnici veliko berejo - že prepričane torej. Ti lahko potem skupaj $\mathrm{z}$ avtorji analizirajo svoje lastne bralne kaprice, se primerjajo $\mathrm{z}$ drugimi knjižnimi molji in rangirajo svoj bralni okus. Samoopazovanje, ki ga sprožijo knjige o branju, lastnim vsakodnevnim srečevanjem $s$ knjigami podeli prav poseben čar. Raznolike književne navade so vsaka zase predstavljene kot svojevrstne in posebne.

\section{Bralni priročniki}

Bralni priročniki niso seveda nič novega. Mednje sodi vse od znamenite klasike How to Read a Book - a Classic Guide to Intelligent Reading (Kako brati knjigo - klasični vodnik inteligentnega branja) Adlerja in van Doreena, ki je bil prvič izdan leta 1940 in potem doživel številne prevode in ponatise, do razlagalnih vodičev po opusih posameznih avtorjev - kakršen je recimo Osbornov How to Read Marx (Kako brati Marxa, 2005) - in priročnikov za hitro branje. Večinoma gre za učbenike in študije, ki se ukvarjajo bodisi s tehnikami branja ali z analizo besedila oziroma žanra, na katerega se nanašajo. Nagel porast tovrstne literature bi si gotovo zaslužil posebno obravnavo, za tukajšnjo razpravo pa sta najbolj zanimiva dva njena novejša tokova: bralni priročniki, pisani $\mathrm{z}$ osebne perspektive, ki navodila podlagajo $\mathrm{z}$ osebnimi pričevanji, in knjige o nebranju - take, ki namesto knjig obravnavajo govorjenje o knjigah.

How to Read and Why (Kako in zakaj brati) Harolda Blooma (2001), How to Read a Novel (Kako brati roman) Johna Sutherlanda (2006), How to Read a Poem and Fall in Love with Poetry (Kako prebrati pesem in se zaljubiti v poezijo) Edwarda Hirscha (2000) in How to Read Literature Like a Professor (Kako brati literaturo kot profesor) Thomasa C. Fosterja (2003) imajo v resnici mnogo značilnosti prej obravnavanih izpovedi knjigoljubcev. Gre za premišljevanja o naravi branja, pisana v dostopnem poljudnem jeziku in v prvi osebi ter na gosto prepredena s subjektivnimi refleksijami, ki so neredko odkrito avtobiografske. Sutherland svojo knjigo denimo opiše kot »vajo iz življenjepisa« $(2006,1)$. 
Tisto, kar ta dela očitno loči od bralnih dnevnikov, je izrazita didaktičnost, ki tudi upravičuje njihovo priročniško naravo. Kljub neformalnemu slogu avtorji namreč ne pišejo v imenu navadnega bralca, temveč nastopajo kot vodniki s poslanstvom, odgovorni za razsvetljevanje bralca s svojim znanjem - to pa je odnos, o katerem v bralnih avtobiografijah ni sledu. Prav zato se v teh knjigah pogosto znajdejo ena in ista pisateljska imena in naslovi, kar se v bralnih dnevnikih in literarnih avtobiografijah zgodi le redko. ${ }^{12}$ To pač niso poročila o bralnih užitkih, zato ugodje branja tudi ni osrednja tema, predvsem pa ni več predstavljeno kot samoumevno, ampak prej kot nekaj, kar si mora bralec šele prislužiti, do česar se mora šele dokopati. Priročniki naj bi pri tem seveda igrali pomembno pomožno vlogo. Bloom govori o »napornem ugodju branja« (2009, 29, poudarek A. Č. V.). Tudi Sutherland meni, da je "romane treba uživati, a pri tem velja, da bolj ko jih beremo, več ugodja lahko iz njih potegnemo« $(2000,12)$. Foster ugodja branja sploh ne omenja, temveč preprosto ponudi orodja za študijsko (ne prostočasno, užitkarsko) branje. Pri tem je zanimivo, da bralni priročniki iz naslova Kako brati [...] praviloma izpuščajo vprašaj, kot da bi želeli s tem tiho sugerirati, da sami ponujajo odgovor na naslovno vprašanje. In prav to je tisto, kar se zdi Virginii Woolf povsem nemogoče: v svojem eseju How should one read a book? (Kako brati knjigo? - z vprašajem vred) izrazi nemoč podati kakršenkoli pameten nasvet:

Najprej želim poudariti vprašaj na koncu mojega naslova. Tudi če bi znala sama odgovoriti na vprašanje, bi se ta odgovor nanašal zgolj name in ne na vas. Edini nasvet glede branja, ki ga lahko damo nekomu drugemu, je, naj ne upošteva nobenega nasveta, naj sledi svojim lastnim instinktom, uporablja svoj razum in pride do lastnih zaključkov. (Woolf, 1935, 258)

Ironično je, da prav ta citat najdemo v številnih bralnih priročnikih, a ga ti kljub temu navadno ne upoštevajo. ${ }^{13}$

Sami napotki glede branja se sicer močno razlikujejo. Kritiški velikan Harold Bloom, ki slovi po zagovarjanju kanona in prizadevanjih, da bi ta

12 Namesto klasikov je ena od skupnih referenc Nelsoninega, Corriganinega in Manguelovega dnevnika 11. september in seznam knjig, ki so jim pomagale prebiti se skozi stresne čase.

13 Gl. na primer Bloom $(2003,20)$ in Sutherland $(2006,23)$. 
obdržal osrednje mesto $\mathrm{v}$ akademskem kurikulumu, odkrito nasprotuje vpeljavi kulturnih študijev in kulturnega materializma na področje literature in temu pripadajočemu obratu od teksta h kontekstu. Njegova predstava o tem, kako brati, napada akademsko poučevanje popularne kulture, interdisciplinarnost in historicizem. Bloom ni naklonjen (pre)usmerjanju pozornosti na kontekstualne dimenzije knjig in branja ali sploh na karkoli, kar presega polje besedilnega.

Nasprotno se John Sutherland, še en sloviti profesor, osredotoča na obrobne sestavine romana in poudarja materialnost knjige in t. i. parabesedila, ${ }^{14} \mathrm{~s}$ čimer bralca ozavesti o številnih, večinoma neopaznih vidikih knjige, kot so pisava, postavitev strani, hvalnice na platnicah, avtorske pravice, platnice, zahvale, predgovori, spremne besede, epigrafi ipd. Sutherland kontekstualizira njihovo vlogo in pomen ter jih zgodovinsko osmisli, pri čemer vseskozi komentira industrijo leposlovja nasploh. Njegova knjiga Kako brati roman je na več načinov razsvetljujoča, predvsem pa z ukvarjanjem s pogosto spregledanimi elementi knjižnega dela obogati izkušnjo branja in sploh srečevanja s knjigo. S sklicevanjem na sezname knjižnih uspešnic, književne nagrade in recenzije avtor sestavi nekakšen zemljevid za orientacijo v neobvladljivem svetu knjig in bralcu pomaga, da se v njem bolje znajde in bolj uživa. Medtem ko Bloom razpravlja o nekaj izbranih naslovih, se Sutherland osredotoči na kontekst in »bralca pouči, kako naj se branja sploh loti« (Guardian, 7. avgusta 2007).

V obeh primerih se od bralca pričakuje, da tudi sam intenzivno bere, saj tovrstni bralni priročniki ne ponujajo obnov in $\mathrm{v}$ nobenem primeru niso nadomestki za pravo literaturo. Čeprav še vedno prisotna, je osebna nota v njih močno stanjšana na račun poučevalne. S stališča literarne izkušnje so bralni priročniki manj samozadostno branje kot bralni dnevniki in nudijo tudi manj bralnega užitka; da bi ga naslovnik doživel, mora zagristi v »pravo« literaturo, tj. v knjige, o katerih se v teh vodnikih »samo« govori.

14 Za natančno obravnavo koncepta parabesedila glej G. Genette. V svojem delu Paratexts (2001) ga definira kot tisto, kar "pospremi« objavljeno delo. Parabesedilo predstavlja »obrobje« tiskanega besedila, ki dejansko nadzira njegovo branje. 


\section{Kniige o nebranju}

Način, kako avtorji razumejo razmerje med branjem in ugodjem, je dober kriterij za razločevanje tipov knjig o branju. Medtem ko bralni dnevniki tako rekoč enačijo eno in drugo, je odnos bralnih priročnikov veliko bolj zadržan: branje in ugodje postavlja le v pogojno razmerje, saj slednje razumejo kot nekaj, kar je mogoče doseči (ali pa vsaj okrepiti) predvsem s pravilnim pristopom, $\mathrm{tj} . \mathrm{z}$ učenjem in znanjem.

Knjige o nebranju ali, natančneje rečeno, o tem, kako govoriti o knjigah, ki jih nismo prebrali, izhajajo iz drugačne predpostavke, ki branje še bolj odveže od užitka. Branje namreč dojemajo kot muko in prav zato - v svetu, kjer branje uživa družbeni ugled - ponujajo bližnjice do splošne načitanosti, s čimer prizadevanja knjig o branju dobesedno postavljajo na glavo.

Ker sta do sedaj, kolikor nam je znano, izšli »samo« dve taki knjigi Comment parler des livres que l'on n'a pas lus (Kako govoriti o knjigah, ki jih niste prebrali, 2007) Pierra Bayarda in How to Really Talk About Books You Haven't Read (Kako zares govoriti o knjigah, ki jih niste prebrali, 2008) Henryja Hitchingsa -, bodo naša spoznanja nujno omejena, še posebej, ker se deli močno razlikujeta. Kljub temu si je najnovejši fenomen bralnih priročnikov vredno pobližje ogledati, saj odpre premislek o zadevah, ki so zelo simptomatične za sodobno bralno kulturo.

Medtem ko obe razpravi predpostavljata, da branje ni ugodje, da pa poznavanje nekaterih knjig obenem ostaja pomembna družbena vrednota, in medtem ko obe delita klepetavo naracijo in pogled navadnega bralca (in to kljub temu, da gre ponovno za profesionalna pisca), ${ }^{15}$ vsaka vendarle ubira izrazito svoj pristop.

Če knjige o branju vselej govorijo o (pre)branih knjigah, knjige o nebranju tega pač ne morejo početi. Namesto tega morajo ponuditi nekaj drugega. Bayard tako opisuje dejanske in fikcijske literarne primere razpravljanja o neprebranih knjigah in spiše prebrisan filozofski traktat o naravi branja, ki obče razumevanje tega pojava postavi pod zelo velik vprašaj. Hitchings

15 Bayard je profesor francoske literature, psihoanalitik in avtor več knjig, med drugim je napisal How to Improve Failed Literary Works in Inquiry Into Hamlet. Hitchings je avtor Dr Johnsons' Dictionary in The Secret Life of Words, piše pa tudi za številne časopise in revije. 
sledi bolj predvidljivemu priročniškemu pristopu. Njegova knjiga je zbir iztočnic za pogovor o delih in avtorjih, ki bi jih povprečen izobraženec moral poznati in ki naj bi nevednemu pomagale narediti vtis intelektualca. Medtem ko Bayard v odgovarjanju na naslovno vprašanje bralca razsvetljuje z veščinami o tem, kako naj pri »blefiranju« o knjigah spretno vnovči tisto, kar že ve o knjigah nasploh, Hitchings ponudi konkretne, vnaprej pripravljene napotke za pogovor. Če je Bayardov vodnik učna ura v epistemologiji in v tem, kako se znajti v knjižnih pomenkih, Hitchingsov priročnik postreže s kratkim kurzom o ključnih literarnih »znamenitostih«, ki naj bi jih nebralec samo zvesto ponovil. Bayardovo pisanje je zato daleč od priročnika in bliže bistroumni in duhoviti refleksiji še ne raziskane teme, ki prepričljivo demonstrira, da tako ali drugače ves čas govorimo o knjigah, ki jih nismo prebrali. Svoje argumente podkrepi s celo vrsto primerov eklatantnega nebranja $\mathrm{v}$ »izvedbi « visoko spoštovanih uglednih osebnosti, kot so Valéry, Wilde in Montaigne, ter knjižnih junakov, kakršen je knjižničar iz Musilovega Moža brez posebnosti ali pariški literati iz Balzacovih Izgubljenih iluzij; za vsa ta dela Bayard trdi, da jih ni prebral. Tako ustvari visokointeligentno študijo, v kateri se norčevanje umika premišljeni meditaciji o človekovem zapletenem odnosu do knjig.

[...] Koncept nebranja je sam po sebi nejasen in zato je pogosto težko zanesljivo reči, kdaj lažemo in kdaj ne, ko trdimo, da smo prebrali neko knjigo. [...] Dejansko je resnica pogosto nekje vmes. Med knjigo, ki smo jo natančno prebrali, in knjigo, za katero nismo niti slišali, obstaja cela vrsta vmesnih postaj, ki si zaslužijo našo pozornost. Če govorimo o knjigah, ki smo jih domnevno prebrali, moramo premisliti, kaj izraz branje pravzaprav pomeni, saj se lahko nanaša na pestro paleto praks. [...] V skladu s tem moramo prilagoditi način, kako govorimo o knjigah, in celo posamezne besede, s katerimi jih opisujemo. (Bayard, 2007, xvi-xviii)

$\mathrm{V}$ ta namen Bayard vpelje štiri kategorije neprebranosti: (a) knjige, ki so mi neznane; (b) knjige, ki sem jih preletel; (c) knjige, o katerih sem slišal; in (d) knjige, ki sem jih pozabil. S tem ko izloči osnovno možnost - prebrane knjige -, pojem branja razrahlja $\mathrm{v}$ niz različic in problematizira njegovo enovito razumevanje. 
Če začne knjiga, takoj ko smo jo prebrali, izginjati iz naše zavesti, vse dokler se niti ne moremo več spomniti, ali smo jo prebrali ali ne, sam pojem prebranosti izgubi svoj pomen, prebrana in neprebrana knjiga se $\mathrm{v}$ tem primeru izenačita. (Bayard, 2007, 55) ${ }^{16}$

Povedano na kratko, njegova teza je, da se večina izjav o neki knjigi ne nanaša na knjigo kot tako in da je zato povsem nepomembno, ali je neka oseba to knjigo prebrala ali ne, saj »tudi če ne pozna natančno njene vsebine, lahko še vedno pozna njeno »lokacijo«, namreč to, kako je umeščena v odnosu do drugih knjig« (Bayard, 2007, 11-12). Tisto, kar je res pomembno, je celostna perspektiva, ki jo Bayard poimenuje kolektivna knjižnica, to pa je mogoče pridobiti tudi z drugimi sredstvi, kot je branje - na primer s prelistavanjem ali preprosto tako, da o knjigi samo slišimo oziroma preberemo. Ko tako izpelje svojo tezo, nazadnje razgrne tudi njen namen:

Govorjenje o neprebranih knjigah sodi v območje pristne ustvarjalnosti [...] Tisto, kar je bistveno, je govoriti o sebi in ne o knjigah oziroma govoriti o sebi skozi knjige. [...] Naša razprava o neprebranih knjigah ponuja privilegirano možnost samoodkritja, ki je blizu avtobiografskemu. (Bayard, 2007, 166, 178-180)

To pa je, ironično, tudi namen in učinek, ki ga tako pogosto navajajo bralni dnevniki in literarne avtobiografije.

Hitchingsov bralni priročnik ubira drugačno strategijo. Čeprav ga je, kot prizna in kar je razvidno že iz naslova, k pisanju spodbudila prav Bayardova knjižica, želi sam k umetnosti pretvarjanja ponuditi drugačen pristop. Potem ko Bayardov prispevek skritizira kot neuporabno abstraktnega, pretirano filozofskega in "francoskega do obisti« (Hitchings, 2008, 21), razgrne svoj radikalno drugačen pristop:

Moj pogled na to, kako govoriti o knjigah, ki jih nisi prebral, je konkreten. Zadeva konkretne knjige in avtorje, o katerih se pogosto pričakuje, da kaj vemo,

16 Čeprav se Bayard v knjigi nadvse trudi, da bi naredil vtis nebralca, v nekem intervjuju le prizna, da »Kako govoriti o knjigah, ki jih niste prebrali, ni tisto, kar se zdi, da je; njen pripovedovalec je fiktivna osebnost, ki se hvali s tem, da ne bere, in to očitno nisem jaz; to pač ni knjiga, ki bi jo napisal nebralec (v: A. Riding: »Read it? No, but you can skim a few pages and fake it«, New York Times, 24. februar 2007). 
in ponudi konkretne strategije za to, kako ravnati z luknjami v našem znanju. (Hitchings, 2008, 22)

Čeprav na začetku predstavi nekaj Bayardu sorodnih stališč in se celo sklicuje na enake zglede, se njegova knjiga hitro spremeni v nekakšen Lonely Planet po literaturi, v tek skozi seznam najpomembnejših del, ta vtis pa še okrepi delitev poglavij na žanre in avtorje oziroma njihova dela. Lov na tiste drobce znanja o literaturi, ki bi bili najprimernejši za to, da jih priložnostno uporabimo v pogovoru, Hitchingsovo knjigo gotovo razloči od ostalih bližnjic do poznavanja kanonskih del. To gre pripisati tudi njegovim duhovitim avtobiografskim pripombam - čeprav se bizarne informacije o avtorjih ali delih, ki jih ponudi, v praksi zdijo pretežno neuporabne. ${ }^{17}$ Hitchings torej ne napiše študije o naravi branja in tudi ne promovira nebranja kot kreativne prakse, temveč skuša nebralca po hitrem postopku seznaniti s temeljnimi deli svetovne literature. V tem smislu seveda prej vzdržuje kot spodnaša uveljavljeno hierarhijo branja nasproti nebranju in vodi stran od Bayardove detabuizacije prelistavanja knjig, posrednega branja in bralnega pretvarjanja. ${ }^{18}$

\section{Sramota in užitek}

Čeprav se mnoge Bayardove ugotovitve zdijo povsem na mestu, velja opozoriti na ne tako nepomembno dejstvo, ki ga, kot se zdi, vseskozi ignorira: namreč na to, da je lahko govoriti o knjigah, ki jih nisi prebral, a šele potem, ko si enkrat že veliko prebral, potem ko že zelo dobro veš, kako »ravnati« s knjigo, skratka, ko si že zgradil solidno notranjo »kolektivno knjižnico«; šele potem boš vedel, kako knjige ne-brati tako, da boš lahko o

17 Hitchings med drugim predlaga, naj se v razpravi o Joyceu pohvalimo s petimi besedami, ki jih je izumil slavni pisec (to so baje: smilesmirk, pornosophical, weggebobble, obstropolos in Scandiknavery) $(2008,66)$.

18 Pomenljivo je, da je Bayardova knjiga izzvala glasen odziv in številne medijske odmeve, medtem ko mi ni uspelo izbrskati niti ene same kritike Hitchingsovega priročnika. Bayardov je prodajna uspešnica v Franciji in ZDA; uvrstil se je med 100 najpomembnejših del leta na lestvici New York Timesa in tudi v Veliki Britaniji prejel prevladujoče pozitivne komentarje. Za nekaj časa je postal celo nekakšno obče mesto, saj so se na njegove teze začeli samoironično sklicevati sami recenzenti, češ da knjige seveda niso prebrali. Nasploh je knjiga spodbudila vrsto duhovitih refleksij, po člankih sodeč pa tudi olajšanja (gl. na primer književne strani v Guardianu zlasti med novembrom 2007 in januarjem 2008). 
njih kljub temu relevantno razpravljal. To lahko potrdi prav vsak akademik. Če poveste, da govorite prek sekundarnih referenc, ni pri tem nič spornega. Res pa je, da so tisti, ki jih neobvladljivost knjižne produkcije najbolj prizadene, prav ljudje, od katerih se pričakuje, da bodo brali natančno in $\mathrm{v}$ celoti, ne pa površno in napol. To so profesionalni bralci in akademiki, a prav ti so v resnici tisti, ki bodo knjige najverjetneje preletavali, da bodo lahko držali korak z novimi naslovi. Po tej logiki je, ironično, najdoslednejše bralce mogoče prej najti med tistimi, ki ne berejo po službeni dolžnosti, temveč v miru in za svoj prostočasni užitek. Profesionalno branje pa nujno vključuje tudi preletavanje in s tem govorjenje o neprebranih knjigah. $\mathrm{V}$ vsem znanem brezizhodnem položaju, ki ga učinkovito ujame naslov knjige Sare Nelson "preveč knjig - premalo časa«, je takšno početje povsem sprejemljivo in celo nujen način preživetja. ${ }^{19}$ Vsekakor pa tega ni lahko priznati. Nedavna anketa $v$ Veliki Britaniji je pokazala, da je na vprašanje, ali so kdaj trdili, da so prebrali knjigo, ki je v resnici niso, 65 odstotkov respondentov odgovorilo $\mathrm{z} » d a \lll .{ }^{20}$ Dejstvo je, da to, če je le mogoče, prikrijemo, sploh če gre za velika znana dela, pa čeravno je zaradi obilice zunanjih referenc o teh najlaže »blefirati«.

Medtem ko se bralni dnevniki in avtobiografije torej vrtijo predvsem okoli občutka ugodja (branja), knjige o nebranju govorijo zlasti o občutju sramu zaradi neprebranega. Užitek in sram sta pravzaprav dve ključni občutenji, ki ju razkrivajo knjige o branju.

Sutherland v uvodu k svojemu vodiču zapiše, da je bil njegov glavni motiv za to, da ga je spisal, prav »občutek sramu pred tem, kako malo leposlovja sem prebral v primerjavi z množico del, ki se ponujajo v branje« (Guardian, 7. avgusta 2007). »Večina med nami bere priložnostno, kar pač

19 Količina izdanih knjig je že davno presegla zmožnost sprotnega branja, v 21. stoletju pa so številke povsem neobvladljive. Leta 2000 je bilo po Zaidu na svetu izdanih približno milijon novih knjižnih naslovov, pri čemer je skupna bibliografija štela kar 52 milijonov (2006, 17-18). Nič čudnega, da se mnoge knjige o branju že v naslovu navezujejo na poplavo knjig, tako da so ti pogosto skorajda zamenljivi. Prim. Zaid: Toliko knjig!, Nelson: Toliko knjig, pa tako malo časa, in prvo poglavje Sutherlandovega priročnika: »Toliko romanov, pa tako malo časa .

20 Izsledki ankete, ki je bila izvedena 5. marca 2009, temeljijo na 1342 odgovorih (gl. http:// www.literacytrust.org.uk/campaign/worldbookday.html). 
nanese, čeprav to neradi priznamo. Ljudje smo glede svojih bralnih navad večinoma neiskreni, « opaža tudi Hitchings $(2008,10)$. A bralni dnevničarji - Nelsonova, Hornby in Corriganova - počnejo prav to: v svojih bralnih popisih razgaljajo, kaj in kako berejo oziroma ne berejo. Hornby (2006) vsako poglavje, $v$ katerem poroča o bralni beri preteklega meseca, prične $s$ seznamom »nabavljenih « in »(pre)branih knjig«, pri čemer precej naslovov s slednjega označi $\mathrm{z}$ »nedokončano« oziroma »opuščeno«.

Če bralni dnevniki torej »odpravijo« občutek sramu glede tega, kaj in kako brati, s tem ko predstavljajo branje kot strast in brez zadržkov spregovorijo o predajanju šundu, Bayard in Hitchings naredita korak naprej in se lotita sramu nebralcev. Tu je sramota namreč dvojna: najprej zato, ker knjige niso prebrali, potem pa še zato, ker o tem lažejo. A tudi priznati resnico je v tem primeru rahlo zadrežno. Eden od ključnih razlogov za to, da se sploh kdo odloči govoriti o neprebrani knjigi, je namreč preprosto v tem, da ne bi izpadel kot nevednež. Po drugi strani pa nam lahko misel na sramoto, ki bi jo doživeli, če bi nas ujeli na laži, prepreči, da bi sploh kdaj razpravljali o čemerkoli, kar nismo prebrali. Bayardova knjiga naj bi tovrstne bojazni vsaj delno omilila. V poglavju z naslovom »Brez občutkov sramu« pojasnjuje, da je "prvi pogoj za to, da govorimo o knjigah, ki jih nismo prebrali, da nas tega ni sram« (Bayard, 2007, 113). Tako kot pisci bralnih dnevnikov vsak sram glede izbora čtiva zavračajo kot neupravičen, tudi knjige o nebranju namreč sporočajo, da lahko prav tako uživamo $\mathrm{v}$ pogovorih o neprebranem. Oba priročnika dokazujeta, da je lahko takšno govorjenje zelo ustvarjalna in nikakor ne sramotna praksa. Tako v knjigah o branju kot o nebranju občutek užitka torej premaga neugodje in sram.

Namesto paternalističnih idej o izobraževanju, razsvetljevanju in učenju (tudi tu) prevlada temeljna zapoved sodobne družbe - uživaj! -, ki razkriva premoč zasebnega interesa nad javnim, kar je povsem v skladu $\mathrm{z} » j \mathrm{jaz}$ « govorico bralnih dnevnikov in avtobiografij. A dejstvo je, da načitanost ostaja pomemben del všečne samopodobe, zato zapoved o užitku predpostavlja: uživajte, ampak berite. Skratka, užitek je vezan na branje. Ostati brez komentarja na prebrano ali neprebrano delo ni obravnavano niti kot možnost. 


\section{Zaključek - razpravljanje »okrog« knjig}

Po vsem, kar smo do sedaj povedali, je mogoče ugotoviti, da knjige o branju vse po vrsti govorijo predvsem »okrog« knjig in ne »o« knjigah samih. Med enim in drugim obstaja pomembna konceptualna razlika. Medtem ko lahko govorimo » $\mathbf{0}$ « knjigi, ki smo jo prebrali, lahko govorimo samo »okrog « knjige, ki je nismo prebrali. Obenem velja, da lahko govorimo tudi »okrog« knjige, ki smo jo prebrali, ne pa tudi »o« knjigi, ki je nismo prebrali. Dosledno prebrana knjiga tako ostaja kategorija zase. Nastajajoči žanr knjig o branju prinaša torej predvsem diskurz okrog knjig. Zdi se, da ta vse bolj zaseda tudi knjižne rubrike v medijih, ki več in več prostora namenjajo temam, ki ne terjajo poznavanja vsebine posameznih literarnih del, temveč so precej bolj splošnega tipa: zadevajo podatke o avtorjih, prodajanosti, okoliščinah nastanka dela ipd. ali so sploh zunajliterarne - sem sodijo denimo opisi delovnih sob pisateljev, njihovih pisateljskih ritualov, seznami najljubših knjig, priporočila za božične knjižne darove itn. ${ }^{21}$ Tudi to je mogoče razumeti kot še en odziv na ekscesno število novih knjig. ${ }^{22}$ Če tovrstne razprave ne zamenjujejo, marveč predvsem dopolnjujejo ožjeliterarne, lahko predstavljajo pomembno obogatitev. Za diskurz okrog knjig namreč velja, da poveže bralce in nebralce ter da pravzaprav širi repertoar knjižnih tem. ${ }^{23}$

Ideja povezovanja med bralci in nebralci ustreza tudi Bayardovim prizadevanjem - kot pove v enem od številnih intervjujev: »Želim, da se ljudje naučijo živeti s knjigami, da bi brali več, ampak z več svobode« (v: A. Riding, New York Times, 24. februarja 2007). Knjiga o nebranju lahko učinkuje tudi kot bralni afrodizijak in nebralce zapelje v svet knjig.

21 Gl. na primer http://www.guardian.co.uk/books/series/writersrooms.

22 Obrat od književnih vsebin k avtorju se sicer zgodi že pred desetletji (gl. študijo A. Vogrinčič: »Literary Effects of the Author Stardom «, v: M. Pennachia Punzi (ur.): Literary Intermediality (2007, 203-218), ki temelji na analizi literarnih strani v dvanajstih evropskih državah med letoma 1960 in 2000). A če je bil premik tedaj povezan predvsem s tabloidizacijo kulturnih strani, se zdijo razlogi zanj danes nekoliko drugačni.

23 Idejo diskurza okrog knjig bi veljalo premisliti v navezavi na koncept »oddaljenega branja « Franca Morettija, ki prav tako zaobide ukvarjanje s samimi literarnimi besedili (gl. Conjectures on World Literature, New Left Review, no. 1 (2000), str. 54-66, in Graphs, Maps, Trees: Abstract Models for a Literary History, 2005); na tem mestu na to samo opozarjamo. 
$\mathrm{V}$ luči povezovanja bralcev in nebralcev je mogoče analizirati tudi aktualne fenomene, kakršni so t. i. twitfic (ang. twitter fiction, tj. leposlovje, pisano in brano prek twitterja), mobi romani, knjižni podcasti in celo vse bolj priljubljena knjižna predavanja, tj. avtorska predavanja na osnovi konkretne, običajno stvarne literature. ${ }^{24} \mathrm{~A}$ pri tem je zanimivo, da prav nobena od vseh treh skupin knjig o branju - niti bralne avtobiografije niti priročniki niti knjige o nebranju - ne naslavlja ali sploh omenja spremenljivih bralnih navad v dobi e-branja, iPhonov, blookov, vookov in kar je še podobnih naprav. ${ }^{25}$ Pogosteje kot ne, te knjige v celoti ignorirajo internetno realnost in se raje prepuščajo udobju branja iz kavča, ki pri »kindlanju « domnevno odpade, kot da bi skušali kar najbolje ujeti občutek avtentičnega branja in tako za potrebe e-prihodnosti zagotoviti zalogo za nostalgična spominjanja na nekdanje bralne prakse.

Knjige o branju so dragocena opazovalnica odnosa do knjig in branja, ponujajo veliko raziskovalnega gradiva in velja jih jemati resno.

\section{LITERATURA}

Adler, M. J., Doren, van C., How to Read a Book: The Classic Guide to Intelligent Reading, New York, 1940.

Bayard, P., How to Talk About Books You Haven't Read, London, 2008.

Bloom, H., How to Read and Why?, London, 2000.

24 Gl. na primer http://www.guardian.co.uk/books/booksblog/2009/may/12/twitter-classicstweetfic za tweetfic; (http://www.amazon.co.uk/Outliers-Story-Success-Malcolm-Gladwell/ $\mathrm{dp} / 1846141214 /$ ref=sr_1_4?ie=UTF8\&s=books\&qid=1251470822\&sr=8-4 za primer knjižnega podcasta in http://www.guardian.co.uk/books/2009/jun/24/live-books-talks-performance-gladwell za opis knjižnih predavanj. Namesto kot grožnjo, tj. kot nekaj, kar izključuje pravo branje in literaturo, velja te novosti jemati kot samostojno obliko izražanja, kot avtonomno izrazno formo. Težko je denimo zanikati duhovitost twitter verzije znamenite Beckettove drame Čakajoč na Godota - »Vladimir and Estragon stand next to tree and wait for Godot. Their status is not updated." - ali privlačnost možnosti preverjanja vsebine neke strokovne knjige z ogledom nekajminutnega videa.

25 Izraz blooks se je v anglosaški literaturi uveljavil za v knjižni obliki objavljene bloge; vook pa je okrajšava za novo medijsko knjigo v obliki videa, t. i. video-book. 
Coleridge, S. T., The Collected Works of Samuel Taylor Coleridge: Volume 5, Princeton, 1987.

Corrigan, M., Leave Me Alone, I'm Reading, New York, 2005.

Doren, van C., The Joy of Reading, Chicago, 2008.

Fadiman, A., Ex Libris: Confessions of a Common Reader, London, 2000.

Foster, T. C., How to Read Literature Like a Professor, New York, 2003.

Furman, L., Standard, E. (ur.), Bookworms: Great Writers Celebrate Reading, New York, 2000.

Gennette, G., Paratexts, Cambridge, 2001.

Hazlitt, W., The Plain Speaker: Opinions on Books, Men and Things, Charlestone, 2008.

Hill, S., Howards End is on the Landing: A year of reading from home, London, 2009.

Hirsch, E., How to Read a Poem and Fall in Love with Poetry, Northam, 2000.

Hitchings, H., How to Really Talk About Books You Haven't Read, London, 2008.

Hornby, N., The Complete Polysyllabic Spree, London, 2006.

Lamb, C., Charles Lamb's Work: The Essays of Elia, Ann Arbor, 2006.

Manguel, A., A Reading Diary, Edinburgh, 2004.

Montaigne, de M., The Complete Essays, London, 2004.

Nelson, S., So Many Books, So Little Time, London, 2003.

Pearl, N., Book Lust, Seattle, 2003.

Quindlen, A., How Reading Changed My Life, New York, 1998.

Rabinowitz, H., Kaplan, R. (ur.), A Passion for Books, New York, 1999.

Riding, A., Read It? No, but You Can Skim a Few Pages and Fake It, New York Times, February 24, 2007.

Schwartz, L. C., Ruined by Reading: A Life in Books, Boston, 1996.

Speed Reading Institute, How to Read Faster and Comprehend More, Manchester, 2007.

Sutherland, J., How to Read a Novel: A User's Guide, London, 2006.

Sutherland, J., How to Read a Novel (an introduction), Guardian, August 7, 2007.

Vogrinčič, A., Literary effects of author-stardom, v: Pennacchia Punzi, M. (ur.), Literary intermediality: the transit of literature through the media circuit, Bern, 2007, 203-218. 
Woolf, V., The Common Reader: Second series, London, 1935.

Woolf, V., The Common Reader, Harmondsworth, 1938. 


\section{BOOKS ON READING AND NOT READING: A SURVEY OF A NEW GENRE}

Keywords: books about reading (and not reading), reading autobiographies, how-to boo ks on reading, (changing) discourse on books

\section{Abstract}

This article examines a growing field of books about reading, some of which openly discuss the practice of not reading, but nonetheless talk about books. After defining the genre, the article identifies its various types and reflects on the changing discourse on the subject, relating it to epistemological transformations of contemporary book culture. 